\title{
How the Cure for Cancer was Discovered
}

\author{
Andrew Hague* \\ Manufacturers of Medical Equipment, UK \\ Received: 眥: November 21, 2018; Published: 制: December 03, 2018 \\ *Corresponding author: Andrew Hague, Manufacturers of Medical Equipment, UK
}

\section{Opinion}

In this account, I must keep places and identities secret but, if you need to know the details, I shall be pleased to tell you in confidence because great emotion is attached to cancer. Everyone expects to die. A man I had known for many years told me that he had prostate cancer and asked if CellSonic VIPP (very intense pressure pulses) could save him. I told him there was a chance. We had a report from a European university that cancer cells were hit with the pressure pulses of the CellSonic type and the replication of mutant cells stopped immediately. There was also a hypothesis from China that pressure kills cancer cells. The authors did not know how to apply the pressure internally so they were only theorising but I knew because the pressure exerted by CellSonic is the same as that used in lithotripsy to fracture kidney stones. The most important consideration was safety. Under no circumstances should the patient be at risk of a cancer being caused or an existing cancer spreading.

The technology in CellSonic goes back forty years when the first non-invasive surgery was invented to break kidney stones. Instead of surgically opening the kidneys, the stones were hit by a lithotripter generating sudden pressure pulses aimed into the body to break the stones into sand small enough to pass through the bladder. Over time, millions of patients had been treated in hospitals in all countries of the world and there were no reports of causing or spreading cancer. I was involved with the first lithotripter in Britain in 1987 and from that had developed CellSonic. On the basis of bad news travelling faster than good news, and there had been no bad news, I was confident that it was safe to treat the cancer patient and the patient, who was in the medical business, agreed. He had the first treatment on a Monday morning. The protocol was 300 pulses per tumour so it took two minutes. No anaesthetic. No drugs. On Wednesday morning he had the second treatment and I telephoned to enquire on progress.

The answer was that the patient was alright. It was unbelievable. He had been dying a few days before. I was angry with them for making a joke in a serious situation so the phone was passed to the patient and his reply was, "I am better now." And he was. His immune system told him that the cancer had gone. Blood tests the following week confirmed it. More patients were treated and again it was on the third day that the patient declared themselves cured. Exactly how the cancer was cured was not understood until a meeting at Bradford University in England a few months later where they divulged their discovery of the different permittivity values for cancer tissues and healthy tissues. In other words, cancer is an electrical fault. That made sense. The CellSonic pulses lasting less than a nanosecond caused by a 25,000-volt arc over a onemillimetre gap were forming a short duration electromagnetic field. In the words of Dr Steve Haltiwanger, we had created a nonsurgical form of irreversible electroporation using a combination of sound waves PLUS a high-powered electric field. This combination had never been done before and Dr Haltiwanger complemented me by saying, "Noble prize work if you can live to collect it. This is a paradigm-breaking disruptive technology. WOW!" We now have a good working theory to explain how CellSonic VIPP works in cancer. It is the combined effect of sound and electric field that produces the unique effects of VIPP. Take away the short duration electrical field and just use sound waves or a slower rise time electrical field you will not see the same effects - which is why CellSonic VIPP technology is different from competitors. 


\section{ISSN: 2574-1241}

DOI: 10.26717/BJSTR.2018.11.002131

Andrew Hague. Biomed J Sci \& Tech Res

(c) (i) This work is licensed under Creative

Submission Link: https://biomedres.us/submit-manuscript.php

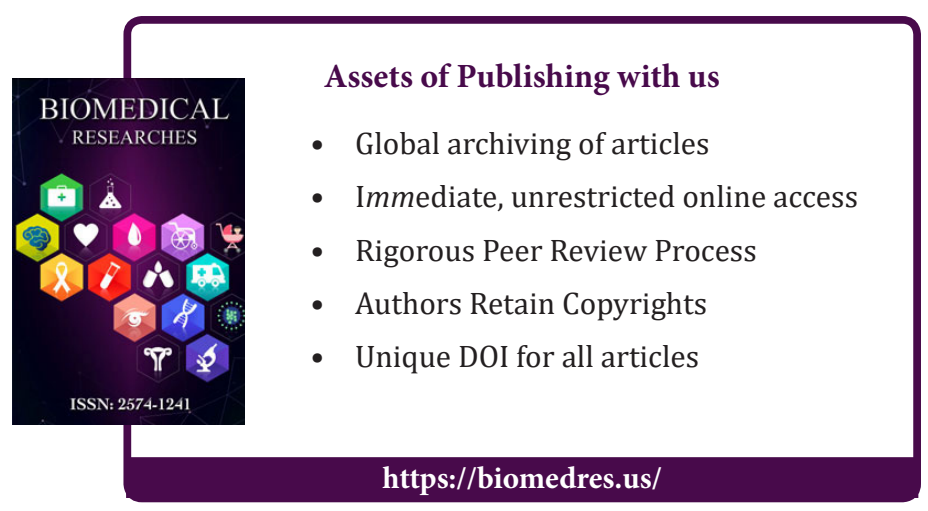

